\title{
MECHANICAL PROPERTIES AND WEAR RESISTANCE OF AI4CU-SiC COMPOSITES FABRICATED BY POWDER METALLURGY
}

\author{
${ }^{1}$ Anna WĄSIK, ${ }^{1}$ Beata LESZCZYŃSKA-MADEJ, ${ }^{2}$ Marcin MADEJ \\ ${ }^{1}$ AGH University of Science and Technology, Faculty of Non Ferrous Metals, Cracow, Poland, EU, \\ anna.wasik@agh.edu.pl, bleszcz@agh.edu.pl \\ ${ }^{2}$ AGH University of Science and Technology, Faculty of Metals Engineering and Industrial Computer \\ Science, Cracow, Poland, EU \\ mmadej@agh.edu.pl
}

https://doi.org/10.37904/metal.2019.767

\begin{abstract}
In the present work Al4Cu-SiC composites were fabricated in a rigid die on a single-action compaction press and then sintered under the nitrogen atmosphere. The SiC $(<2 \mu \mathrm{m})$ content was 5 and $10 \mathrm{wt} \%$. An attempt has been made to study the mechanical and tribological properties of fabricated materials. The microstructure of composite materials was analyzed with scanning electron microscopy (SEM) and X-ray diffraction (XRD). The obtained results indicated that introduction the ceramic particles into Al4Cu matrix resulted in an increase of most mechanical properties compared to the matrix material. However, the tribological properties were higher for unreinforced Al4Cu matrix than for composites with the addition of SiC.
\end{abstract}

Keywords: Metal matrix composites, powder metallurgy, tribology, mechanical properties, microstructure

\section{INTRODUCTION}

This paper considers the examination of aluminum alloy metal matrix composites (MMC) reinforced with silicon carbide particles. The addition of $\mathrm{SiC}$ as a reinforcement to $\mathrm{Al}$ matrix has justification in its properties that are characterized by low density, high hardness and resistance to abrasion and corrosion, which makes it an attractive material used in the automotive and aerospace industry [1]. Powder Metallurgy (PM) is one of the most widely used method of producing the MMC. During determining the process parameters in the production of composite materials by PM, many factors should be taken into consideration. For example, Liu et al. [2] have observed that a uniform distribution of $\mathrm{SiC}$ particles improves yield strength and ultimate tensile strength of $\mathrm{SiC} / 2024 \mathrm{Al}$ composites. However, the ceramic reinforcing particles tend to form clusters, which influence on the overall mechanical properties of composites [3]. Ferdemir et al. [4] indicated that non-uniform distribution of $\mathrm{SiC}$ particles may cause the decrease in ductility and fracture toughness, which is an obstacle preventing their extensive use. Kassim et al. [5] reported that abrasion resistance is improved by the introduction of SiC particles reinforcement. Moreover, Kumar et al. [6] have shown that as well as volume fraction of $\mathrm{SiC}$, also its particle size have strong influence on tribological properties. It was found that reducing the particle size of reinforcement allowed for a reduction in the wear rate. Ganesh et al. [7], who studied the effect of sintering temperature on mechanical properties of Al matrix composites, provided information that higher sintering temperature favors the growth of mechanical properties. The difficulty in obtaining the proper connection quality in composite is the difference in the values of coefficients of thermal expansion between the metal matrix and the ceramic reinforcement. Increasing the content of the reinforcing phase in matrix material hinders obtaining a high degree of compaction [8]. El-Kady et al. [9] reported the decrease of densification of extruded $\mathrm{Al}$ matrix composites with the increase of $\mathrm{SiC}$ content. The obtained results in this article have a significant impact on the development of materials science, due to the fact that they allow for a detailed analysis of mechanical and tribological properties of composite materials formed by metal and ceramics component by powder metallurgy method. 


\section{EXPERIMENTAL}

Examined composite materials were based on $\mathrm{Al}-4 \mathrm{wt} \% \mathrm{Cu}$ alloy with the addition of 5 and $10 \mathrm{wt} \%$ of silicon carbide as reinforcement. Based on data provided by manufacturer the size of argon gas-atomized aluminum (Al 1050) and electrolytic copper powder was below $63 \mu \mathrm{m}$. The reinforcing phase was in the form of particulates with an average grain size below $2 \mu \mathrm{m}$. The particles of aluminum powder atomized by argon were a mixture of elongated particles and irregularly shaped particles characterized by a relatively smooth surface. The copper powder has the dendritic shape of particles with a large number of branches and strongly developed surface characteristic for electrolytic manufacturing. Silicon carbide powder has generally irregular shape. Composite powders based on aluminum containing $4 \mathrm{wt} \%$ of copper reinforced with silicon carbide ceramic particles have been consolidated by conventional powder metallurgy rout included mixing, uniaxial cold die pressing and sintering. Copper-alloyed aluminum powders were mixed along with various weight fraction of $\mathrm{SiC}$ reinforcement for 30 minutes in a Turbula T2F mixer. The blended powders were put into a rigid die and compacted under a single - action compaction press applying pressure of $300 \mathrm{MPa}$. The matrix walls were lubricated with glycerine to prevent powder adhesion to the matrix and reduce external friction. In the next step of consolidation the green bodies were subjected to the sintering process for 60 minutes in a three zone tube furnace using a protective atmosphere of nitrogen. The sintering temperature was equal to $600{ }^{\circ} \mathrm{C}$. To provide better densification of produced composite materials, the double pressing and double sintering operations $(2 \mathrm{p} 2 \mathrm{~s})$ under the same conditions were applied. In order to determine the degree of porosity, the density of obtained composite materials was measured at each step of preparation using geometric method.
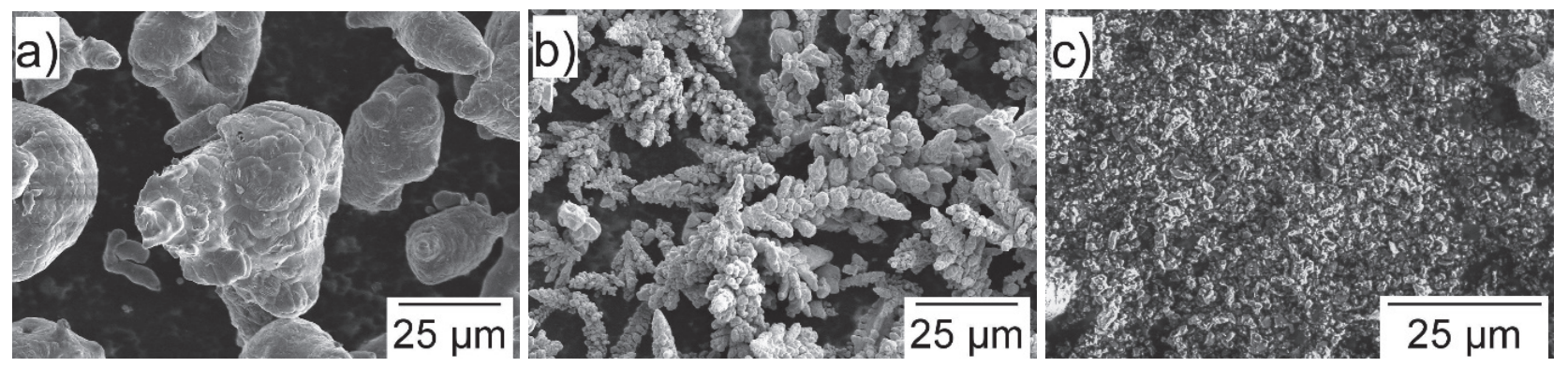

Figure 1 SEM micrographs of starting powders of: a) aluminum, b) copper, c) silicon carbide

The microstructural characteristics were performed by Scanning Electron Microscope (SEM) with Thermo Scientific NORAN System 7 X-ray microanalysis system (EDS) - Hitachi SU70. Additionally, information about phase composition of samples was provided by the X-ray diffraction (XRD) analyses (Brucker Co Ka $=0.197$ $\mathrm{nm}$ radiation). The mechanical properties of $\mathrm{Al} 4 \mathrm{Cu}-\mathrm{SiC}$ composites were determined by the hardness measurement, determination of compression strength and bending strength. The hardness test was carried out using the Brinell method. The test used a $2.5 \mathrm{~mm}$ diameter tungsten carbide ball as an indenter with a 613 $\mathrm{N}$ force. The compression and bending tests were performed at room temperature on a universal testing machine Zwick Roell Z050 strength tester. The compression test was conducted at an initial strain rate of $8 \cdot 10^{-3} \mathrm{~s}^{-1}$. The three-point bending test was carried out at a constant tool feed speed of $0.005 \mathrm{~mm} / \mathrm{s}$. The support span was $28 \mathrm{~mm}$. The tribological properties of Al4Cu - SiC samples (20 mm x $4 \mathrm{~mm} \times 4 \mathrm{~mm}$ ) were tested in a block on roller tribotester T-05 at ambient temperature in dry friction conditions. The counter sample with diameter of $49.5 \mathrm{~mm}$ made of heat treated $100 \mathrm{Cr} 6$ bearing steel and with hardness of $55 \mathrm{HRC}$ have been used. All wear tests were conducted with sliding speed of $136 \mathrm{rpm}$ for the entire test in dry conditions. The tests were carried out under the constant load of $56 \mathrm{~N}$. The sliding distance with track diameter of $500 \mathrm{~m}$ was used to record the friction coefficient change. To determine the mechanisms of wear the wear surface was analyzed using scanning electron microscopy. 


\section{RESULTS AND DISCUSSION}

Table 1 presents the density data at different stage of compaction of investigated materials. The addition of silicon carbide particles into the Al4Cu matrix increases the density of the composite materials in comparison to pure matrix material. The results show that re-pressing and re-sintering operations allow increase the degree of densification of both matrix material and composites with the addition of SiC. Sintering process provides conditions for diffusion of atoms to limit the amount of pores and thus increase density. The highest degree of densification, at the final stage of production, was characterized by an aluminum alloyed matrix. The addition of a hard reinforcing phase in ductile matrix hinders the pressability of the material. Therefore, the pressability of the Al4Cu-SiC composites decreases with the increasing the content of reinforcing particles. The compaction densification mechanism of composite material is mainly facilitated by plastic deformation and diffusion along grain boundaries. However, in composites with the addition of reinforcing phase, the presence of $\mathrm{SiC}$ particles hinders diffusion at the grain boundary and lowering its mobility due to "grain pinning" by particles of the second phase, causing an increase in resistance to compaction [10].

Table 1 Variations of density at different level of compaction

\begin{tabular}{|c|c|c|c|c|c|}
\hline Material & $\begin{array}{c}\text { Theoretical } \\
\text { density }\left(\mathrm{g} / \mathrm{cm}^{3}\right)\end{array}$ & $\begin{array}{c}\text { Green density } \\
(\%)\end{array}$ & $\begin{array}{c}\text { Sintering } \\
\text { density }(\%)\end{array}$ & $\begin{array}{c}\text { Re-press } \\
\text { density }(\%)\end{array}$ & $\begin{array}{c}\text { Re-sintered } \\
\text { density }(\%)\end{array}$ \\
\hline $\mathrm{Al} 4 \mathrm{Cu}$ & 2.77 & 86.86 & 89.87 & 91.57 & 92.03 \\
\hline $\mathrm{Al} 4 \mathrm{Cu}-5 \% \mathrm{SiC}$ & 2.80 & 82.83 & 87.31 & 89.54 & 91.76 \\
\hline $\mathrm{Al} 4 \mathrm{Cu}-10 \% \mathrm{SiC}$ & 2.82 & 81.03 & 84.25 & 85.21 & 88.45 \\
\hline
\end{tabular}
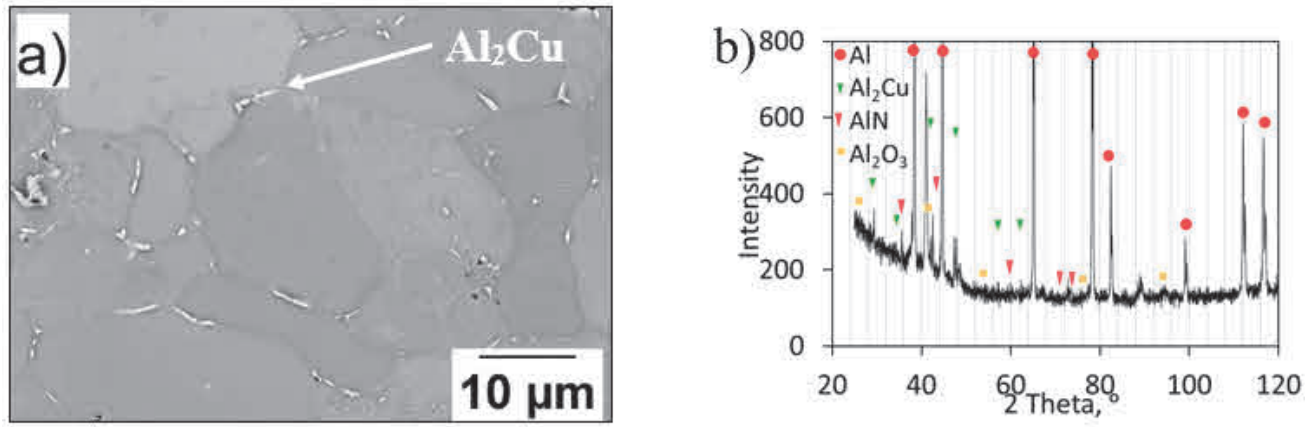

Figure 2 SEM images (a) and X-ray diffraction patterns (b) of Al4Cu matrix
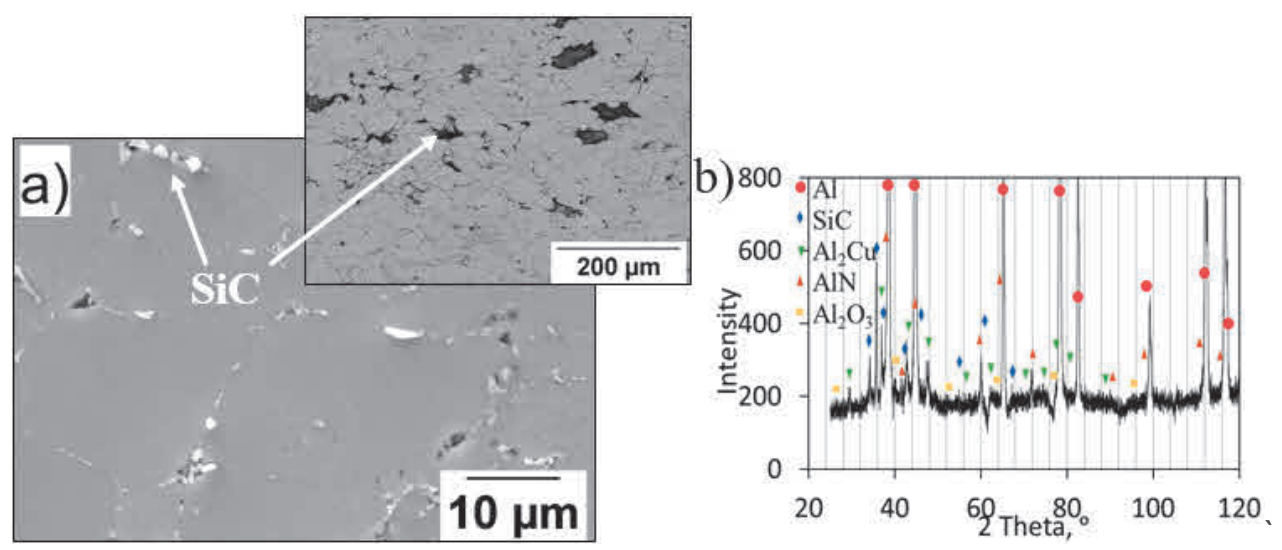

Figure 3 SEM images (a) and X-ray diffraction patterns (b) of Al4Cu-5 wt $\%$ of SiC composite

Figures 2a and 3a show SEM images of Al4Cu matrix and Al4Cu - 5 wt $\%$ of SiC composite, respectively. The microstructure of as-sintered matrix and composite material consists mainly of regular aluminum grains and 
scare pores located at the grain boundaries. There are additionally visible some precipitates reveal the primary grain boundaries as they form a continuous network spread along the Al powder particles. According to the Xray diffraction patterns the precipitates corresponds to the composition of $\mathrm{Al}_{2} \mathrm{Cu}$ phase (Figures $\mathbf{2 b}, \mathbf{3 b}$ ). The XRD analysis reveals also the presence of $\mathrm{Al}_{2} \mathrm{O}_{3}$ oxides and $\mathrm{AIN}$ nitrides in microstructure. The presence of oxides is associated with the strong affinity for oxygen of aluminum. In order to form diffusion bonds between powder particles, exposed, oxide-free active powder surfaces are necessary. The oxide film undergoes partial breaking during compaction due to the friction occurred between particles. During the sintering process, the oxide layer breaks due to the stress formation as results of difference in the thermal expansion coefficient between aluminum and aluminum oxides. The reason for the formation of aluminum nitrides is the application of nitrogen as a sintering atmosphere in sintering process of tested materials. In as-sintered $\mathrm{Al} 4 \mathrm{Cu}-5 \mathrm{wt} \%$ of $\mathrm{SiC}$ composite the silicon carbide particles are additionally visible on the grain boundaries. The particles of reinforcing phase are found to be homogenous distributed. However, mixing the composite powders in Turbula mixer did not allow to avoid the SiC phase agglomeration formation.

The effect of the addition of $\mathrm{SiC}$ reinforcement on the hardness and bending strength of composite materials is shown in Figure 4 and Figure 5, respectively. Introduction the ceramic particles into Al4Cu matrix resulted in an increase in hardness compared to the matrix material. The increase in hardness of the composite materials corresponds to the formation of dislocations in the form of dislocations loops on the metal - ceramic interface due to the thermal expansion coefficient mismatch between the matrix and reinforcement. However, the hardness of composite materials was maintained at an equal level of around $67 \div 68 \mathrm{HB}$, regardless of the weight fraction of the reinforcing phase. Moreover, the highest resistance to bending is characterized by the matrix of tested materials without the addition of reinforcement. Reinforcement with hard SiC phase resulted in a marked decrease in bending strength in relation to the matrix material which progresses with the increase of the reinforcement content from the value of $847 \mathrm{MPa}$ given for the Al4Cu matrix to $191 \mathrm{MPa}$ given for the reinforced composites with the addition of $10 \mathrm{wt} \%$ of $\mathrm{SiC}$. The obtained results correspond to the morphology of SiC particles (irregular shape). Their sharp edges can promote crack initiation during bending. Silicon carbide is a brittle phase and fine-grained form clusters in-between the larger particles of matrix, which hinders the homogeneous distribution of the reinforcing phase in the matrix while mixing in the Turbula mixer and also contributes to cracking.

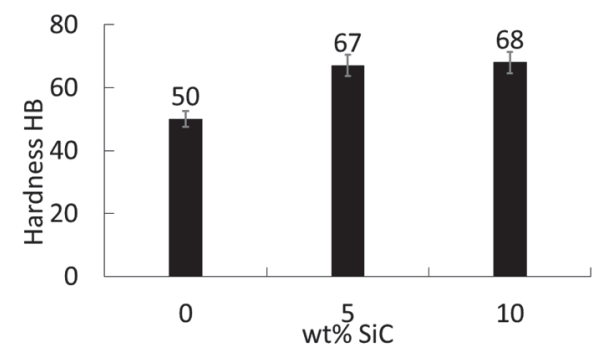

Figure 4 Effect of SiC content on Brinell hardness of Al4Cu-SiC composites

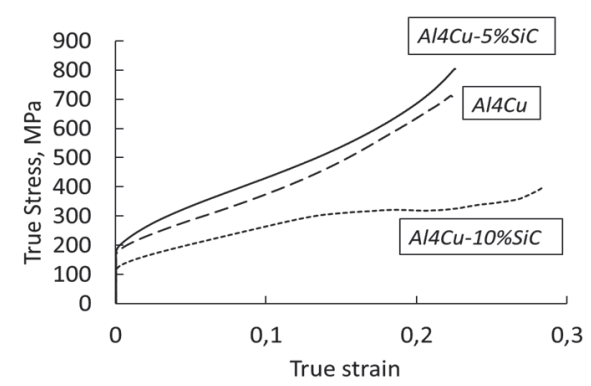

Figure 6 Stress - strain curve behavior

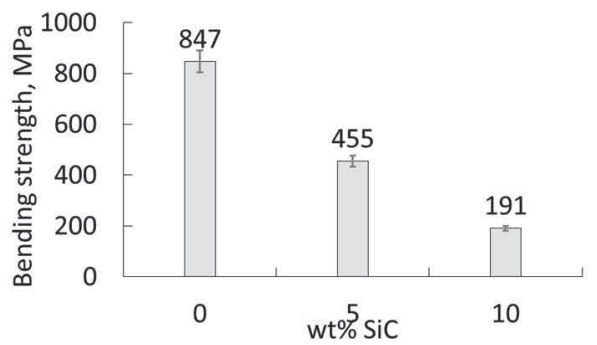

Figure $5 \mathrm{Effect}$ of $\mathrm{SiC}$ content on bending strength of Al4Cu-SiC composites

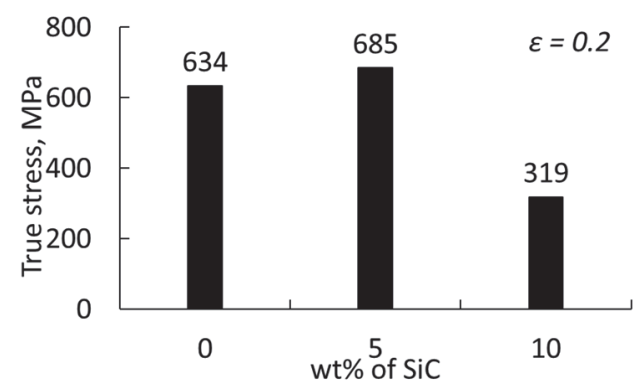

Figure 7 Values of real stresses with a real strain equal to 0.2 
Change in weight fraction of $\mathrm{SiC}$ particles has a strong influence on the character of the stress-strain curves (Figure 6). The highest strength was obtained for the composite reinforced with $5 \mathrm{wt} \%$ of $\mathrm{SiC}$. For higher $\mathrm{SiC}$ content the strength was lower than for the pure Al4Cu matrix. Measured value of true stress of materials subjected to compression test with a true strain equal to 0.2 was $685 \mathrm{MPa}$ for composite with the addition of 5 $\mathrm{wt} \%$ of $\mathrm{SiC}$, while increasing the weight fraction of reinforcement to $10 \mathrm{wt} \%$ caused the mechanical properties deterioration due to the lower work hardening and true stress decreased up to $319 \mathrm{MPa}$ (Figure 7). For comparison, the value of the compressive stress of the pure matrix under the same strain conditions was 634 $\mathrm{MPa}$. Although the fine-grained reinforcement particles affects the movement of the dislocations, hence the higher number of $\mathrm{SiC}$ particles the smaller the distance between the particles of reinforcement, which should make strengthening become more effective, the compressive strength of the composite materials reinforced with $10 \mathrm{wt} \%$ of $\mathrm{SiC}$ seems not to be improved by SiC particle reinforcement. Deterioration of mechanical properties due to increased $\mathrm{SiC}$ phase content may be an effect of internal stresses concentration and initiation of cracks at the sharp edges of SiC particles. In addition, the introduction of higher amount of hard phase into the matrix hinders the compaction process, as a result of which the material is characterized by a higher porosity, indicating insufficient consolidation of the powders compared to the matrix material.

The Figures 8 and $\mathbf{9}$ show the effect of increase of weight fraction of reinforcement on coefficient of friction and weight loss for Al4Cu matrix composites, respectively. Lower values of coefficient of friction were achieved for the Al4Cu matrix composites. Coefficient of friction initially increases with increase in weight fraction of SiC (from 0.417 for matrix material to 0.794 for composite material with the addition of $10 \mathrm{wt} \% \mathrm{of} \mathrm{SiC}$ ). High values of coefficient of friction indicate the presence of complex mechanisms of friction, including the phenomena of adhesion and cracking. It can be seen from the graphs that weight loss for unreinforced AICu matrix was smaller than for composites with the addition of SiC particles (Figure 9). Although the rate of weight loss in matrix material and composites with the addition of $5 \mathrm{wt} \%$ of $\mathrm{SiC}$ was similar, at higher content of reinforcing phase it is noticeable that weight loss rapidly increased. It might be associated with the fact that $\mathrm{SiC}$ particles are being "pulled-out" from the matrix during the process of friction.

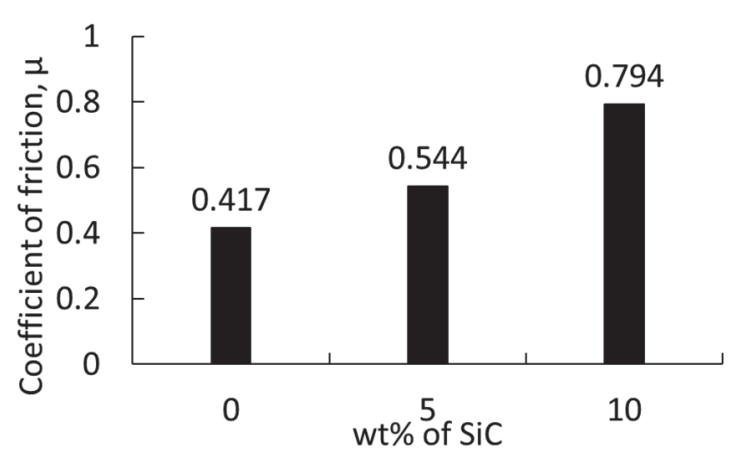

Figure 8 Variation of coefficient of friction

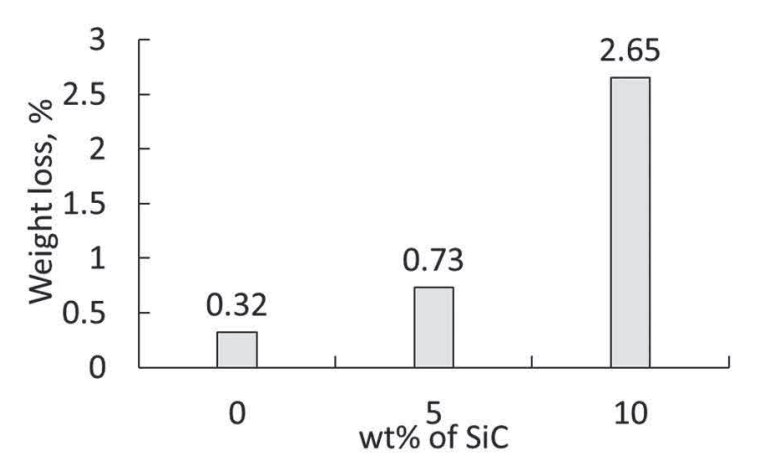

Figure 9 Variation of weight loss
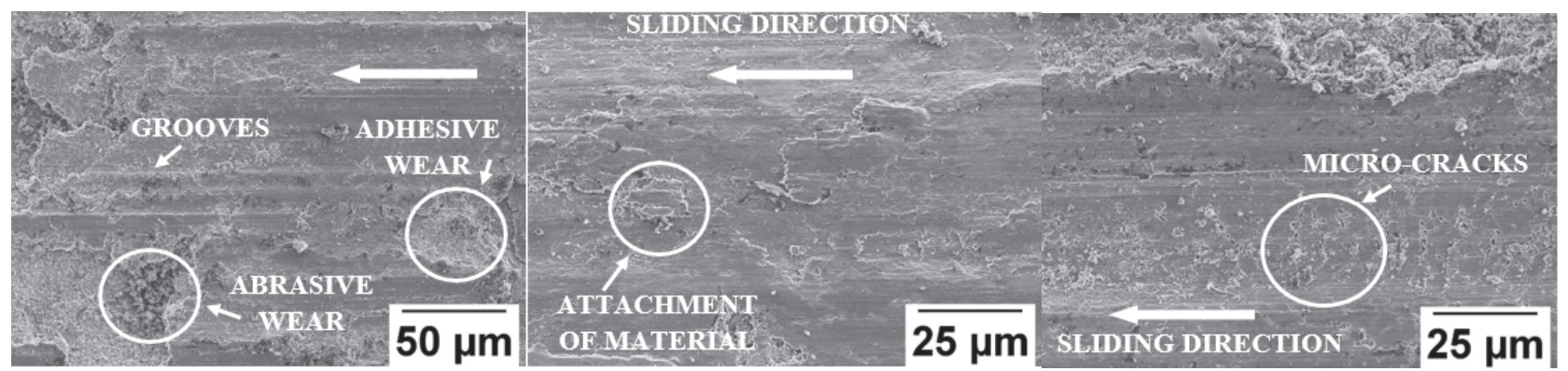

Figure 10 The $\mathrm{Al} 4 \mathrm{Cu}$ - $10 \% \mathrm{SiC}$ samples surfaces after tribological tests; SEM 
Figure 10 shows the worn surfaces of the selected $\mathrm{SiC}$ reinforced $\mathrm{Al} 4 \mathrm{Cu}$ matrix composites. The analysis of the samples surfaces after tribological tests indicates the wear phenomenon occurring in Al4Cu-SiC composites is a combination of surface fatigue, abrasive and adhesive wear. Longitudinal grooves in plastic matrix caused by hard SiC particles moving along a softer surface were observed. The pulling out of SiC phase and its rolling along between friction surface and counter-sample resulting in scratching the surface, which contributes to increase the effect of abrasive wear in composites. Undesirable displacement and attachment of the material compounds has been observed. Such behavior is generally characteristic for effect of adhesive wear. The accumulation of the crushed products of wear in the wear surface is visible. This phenomenon leads to the surface strengthening of the material. The surfaces show the occurrence of transverse micro-cracks growing toward the direction of the friction and plastic flow of a part of material. These micro-cracks indicate the effect of surface fatigue caused by weakness of the surface of material due to the cyclic loading.

\section{CONCLUSION}

The addition of silicon carbide particles into the Al4Cu matrix hinders the densification of the composite materials in comparison to pure matrix material. Re-pressing and re-sintering operations allow to increase the degree of densification of both matrix material and composites with the addition of SiC by approximately of 4 $\%$ in comparison to single sintering. The microstructure of both matrix and composite materials is characterized by a precipitates of coarser $\mathrm{Al}_{2} \mathrm{Cu}$ phase on the grain boundaries. The presence of aluminum nitrides, due to sintering under nitrogen atmosphere, and aluminum oxides, due to strong affinity for oxygen of aluminum, was observed. The SiC particles are relatively homogeneously distributed in the matrix, however, formation of the agglomerates of reinforcing phase has been also observed. Introduction the ceramic particles into Al4Cu matrix resulted in an increase of hardness from $50 \mathrm{HB}$ to $68 \mathrm{HB}$ and in a decrease in bending strength in relation to the matrix material which progresses with the increase of the reinforcement content from $847 \mathrm{MPa}$ to $191 \mathrm{MPa}$. The compressive strength of the composite material reinforced with $10 \mathrm{wt} \%$ of SiC seems not to be improved by SiC particle reinforcement. Coefficient of friction and weight loss for unreinforced Al4Cu matrix is lower than for composites with the addition of $\mathrm{SiC}$ reinforcement. The main wear mechanism for $\mathrm{Al} 4 \mathrm{Cu}-\mathrm{SiC}$ composites is a combination of surface fatigue, abrasive and adhesive wear.

\section{ACKNOWLEDGEMENTS}

The financial support of the Polish State Committee for Scientific Research under the grant number 16.16.180.006 is kindly acknowledged.

\section{REFERENCES}

[1] NAYAK, K.C. and DATE, P.P. Hot deformation flow behavior of powder metallurgy based $\mathrm{Al}-\mathrm{SiC}$ and $\mathrm{Al}_{-} \mathrm{Al}_{2} \mathrm{O}_{3}$ composite in a single step and two-step uni-axial compression. Materials Characterization. 2019. vol. 151, pp. 563-581.

[2] LIU, Z.Y., WANG, Q.Z., XIAO, B.L., MA, Z.Y. and LIU, Y. Experimental and modeling investigation on SiCp distribution in powder metallurgy processed SiCp/2024 Al composites. Materials Science and Engineering: $A$. 2010. vol. 527, no. 21-22, pp. 5582-5591.

[3] CANAKCI, A. and VAROL, T. Microstructure and properties of AA7075/AI-SiC composites fabricated using powder metallurgy and hot pressing. Powder Technology. 2014. vol. 268, pp. 72-79.

[4] ERDEMIR, F., CANAKCI, A. and VAROL, T. Microstructural characterization and mechanical properties of functionally graded Al2024/SiC composites prepared by powder metallurgy techniques. Transactions of Nonferrous Metals Society of China. 2015. vol. 25, pp. 3569-3577.

[5] AL-RUBAIE, K.S., YOSHIMURA, H.N. and MELLO, J.D.B. Two-body abrasive wear of Al-SiC composites. Wear. 1999. vol. 233, pp. 444-454. 
[6] KUMAR, S. and BALASUBRAMANIAN, V. Effect of reinforcement size and volume fraction on the abrasive wear behaviour of AA7075 Al/SiCp P/M composites-A statistical analysis. Tribology International. 2010. vol. 43, pp. 414-422.

[7] GANESHA, R., SUBBIAH, R. and CHANDRASEKARAN, K. Dry Sliding Wear Behavior of Powder Metallurgy Aluminium Matrix Composite. Materials Today: Proceedings. 2015. vol. 2, pp. 1441-1449.

[8] MURTHY, H.C., RAJU, V.B. and SHIVAKUMARA, C. Effect of TiN particulate reinforcement on corrosive behavior of aluminium 6061 composites in chloride medium. Bull. Mater. Sci. 2013. vol. 36, no. 6, pp. 1057-1066.

[9] EL-KADY, O. and FATHY, A. Effect of SiC particle size on the physical and mechanical properties of extruded Al matrix nanocomposites. Materials \& Design. 2015. vol. 54, pp. 348-353.

[10] JAYAKUMAR, K., JOSE, M., JOSEPH, M.A., KUMAR, R.S., SHUKLA, A.K. and SAMUEL, M.G. Synthesis and characterization of A356-Sicp composite produced through vacuum hot pressing. Mater. Manuf. Process. 2013. vol. 28, pp. 991-998. 